\title{
Predictors of Obesity among Adolescents in Ekiti State, Nigeria
}

\author{
Raimi $\mathrm{TH}^{1}$, Oluwayemi IO ${ }^{2 *}$ and Oluwayemi $\mathrm{MA}^{3}$ \\ ${ }^{1}$ Department of Medicine, Ekiti State University, Nigeria \\ ${ }^{2}$ Department of Paediatrics, Ekiti State University, Nigeria \\ ${ }^{3}$ Deparment of Nursing services, Ekiti State University Teaching Hospital , Nigeria \\ *Corresponding author: Isaac Oludare Oluwayemi, Department of Paediatrics, Faculty Clinical Sciences, Ekiti State University, Nigeria \\ Submission: :-1; May 21, 2018; Published: 眥 May 31, 2018
}

\begin{abstract}
Background: Childhood and adolescents obesity is a public health challenge. Studies on predictors of obesity among children in developing countries are very few. The aim of the index study is to determine the predictors of childhood obesity in Ekiti State, Nigeria.

Methods: The index study was a cross-sectional study among secondary school adolescents in Ekiti State. After receiving Government approval and school permission to enter the schools, structured questionnaires were administered to students whose parents gave consent to participate in the study. Measurement of weight, height, waist circumference, blood pressure, and fasting blood glucose were done following standard procedures. Binary logistic regression was employed to determine the predictors of obesity

Results: 346 (55.1\%) males and 282 females (44.9\%) participated in the study. More females than males were in the low/middle social class ( $25.2 \%$ vs. $14.2 \%, \mathrm{p}<0.001)$, consumed more snacks $(91.8 \%$ vs. $85.5 \%$, $\mathrm{p}=0.014)$, and had general obesity $(13.2 \%$ vs. $2.3 \%$, $\mathrm{P}<0.001)$. The mean BMI, SBP, DBP and FBG were significantly higher ( $<<0.001)$ in female compared to male students: BMI, 20.39(2.82) kg/m² vs. 19.27(2.14) kg/m²; SBP, 122.61(13.91) mmHg vs. 114.36(14.82) mmHg; DBP, 75.76(10.96) mmHg vs. 65.29(9.69) mmHg; FBG, 97.60(10.52) mg/dl vs. 93.40(10.84) mg/dl. Female gender [OR (95\%CI), 8.685(3.872-19.483), $\mathrm{p}<0.001$ ] and attending public school [OR (95\%CI), 8.149(1.047-63.426, $\mathrm{p}=0.045)$, were the only factors found to be predictive of obesity.
\end{abstract}

Conclusion: Female gender and type of school attended were the predictors of obesity in secondary school adolescents in Ekiti State. Lifestyle changes targeted at female students in public schools may help curb obesity prevalence in the State.

Keywords: Obesity; Adolescents; Predictors; Ekiti state; Nigeria

\section{Introduction}

Childhood obesity is becoming a public health concern [1-4]. This is because it is associated with significant morbidity such as hypertension, premature puberty/adrenache, hypovitaminosis D, osteopenia/ osteoporosis and mortality [5-7]. It is also a risk factor for adult obesity $[8,9]$. The prevalence of childhood obesity globally ranges from $0.1 \%$ to $14 \%$ with higher rates in Europe [10]. In Nigeria, childhood obesity occurs in $3.3 \%$ of children $[10,11]$. As Nigerians adopt western lifestyles, the prevalence of obesity is expected to increase among children and adults. Obesity is a preventable disease. Identification of its predictors among children will help to mount effective preventable strategies. Prevention of childhood obesity may help curb the scourge of adult obesity, in addition to its associated morbidity.

Recognized risk factors and predictors of childhood obesity include birth weight, weight gain in infancy, maternal obesity, gestational weight gain, and maternal smoking during pregnancy [12-14]. Other factors implicated in the rising prevalence of childhood obesity include: lower socioeconomic status, little physical activity, watching television and consumption of energydense foods [13-16]. What are the predictors of childhood obesity in Nigeria, and are these predictors preventable? This study aims to answer these questions.

\section{Materials and Methods}

The index study was a cross sectional study involving apparently healthy secondary school adolescents from one private and two public secondary schools in Ado-Ekiti, Ekiti State, Nigeria. Ethical clearance and permission to enter the schools was obtained from the Research and Ethical Committee of the Ekiti State University Teaching Hospital, Ado-Ekiti and The Ministry of Education, Ekiti State respectively. Students aged 10-19 years who gave assent and whose parent/guardian gave written consent were recruited. Prospective study subjects reported at 7.30am at an agreed upon 
study room within the school premises made available by the school authorities. Subjects fasted overnight with their agreedupon last meal being $9 \mathrm{pm}$ the previous night of the day for the study. A structured questionnaire was administered to obtain socio-demographic data and information relevant to the study. Weight, height, waist circumference (WC), hip circumference and blood pressure were measured using standard procedures [17]. BMI was calculated as weight in kilogram divided by the square of height in meter $\left(\mathrm{kg} / \mathrm{m}^{2}\right)$. Using these measurements and BMIfor-age percentiles charts by the US Centers for Disease Control and Prevention (CDC) [18], the weight status of each subject was categorized as follows: obese ( $\geq 95$ th percentile); overweight (85th to $<95$ th percentile); normal weight (5th to $<85$ th percentile); underweight $(<5$ th percentile). Blood Sampling: capillary blood sample for fasting blood glucose was measured using Accu-Chek Active ${ }^{\circledR}$ glucometer (Roche Diagnostic). The test result was discussed with participants and counseled appropriately. Each participant was given an apple fruit to break their fast after the study. Fasting blood glucose (FBG) was classified according to the recommendation of American Diabetes Association [19] which states that $\mathrm{FBG} \geq 7.0 \mathrm{mmol} / \mathrm{L}(126 \mathrm{mg} / \mathrm{dL})$ is provisional diagnosis of diabetes; FBG $5.6-6.9 \mathrm{mmol} / \mathrm{L}(100-125 \mathrm{mg} / \mathrm{dL})$ is impaired fasting glucose and FBG $<5.6 \mathrm{mmol} / \mathrm{L}(100 \mathrm{mg} / \mathrm{dL})$ is normal fasting glucose.

Data analysis was done with SPSS (IBM Inc. US) version 20. Categorical data was presented in percentages, and compared with Chi-Square, while continuous data was presented as mean (standard deviation) and compared with Student's t-test. Binary logistic regression was employed to determine the predictors of obesity among the participants. Level of significance was set as $\mathrm{p}<0.05$.

\section{Results}

Table 1: Comparison of the clinical profile of male and female adolescents.

\begin{tabular}{|c|c|c|c|}
\hline Characteristics & Male $\mathrm{N}=346$ & Female $\mathrm{N}=\mathbf{2 8 2}$ & $\mathbf{P}$ \\
\hline Continuous variables & Mean (SD) & Mean (SD) & \\
\hline Age (years) & $14.47(1.82)$ & $13.93(1.58)$ & $<0.001$ \\
\hline Weight (kg) & $46.89(10.03)$ & $47.48(8.46)$ & 0.426 \\
\hline Height (m) & $1.55(0.11)$ & $1.52(0.08)$ & $<0.001$ \\
\hline BMI $\left(\mathrm{kg} / \mathrm{m}^{2}\right)$ & $19.27(2.14)$ & $20.39(2.82)$ & $<0.001$ \\
\hline $\mathrm{WC}(\mathrm{cm})$ & $67.41(5.25)$ & $68.22(6.04)$ & 0.078 \\
\hline SBP & $114.36(14.82)$ & 122.61(13.91) & $<0.001$ \\
\hline DBP & $65.29(9.69)$ & $75.76(10.96)$ & $<0.001$ \\
\hline FPG & $93.40(10.84)$ & $97.60(10.52)$ & $<0.001$ \\
\hline Categorical variables & Frequency (\%) & Frequency (\%) & \\
\hline Obesity & & & $<0.001$ \\
\hline Normal & $338(97.7)$ & $243(86.2)$ & \\
\hline Obese & $8(2.3)$ & $39(13.2)$ & \\
\hline Social class & & & $<0.001$ \\
\hline Lower/middle & $49(14.2)$ & $71(25.2)$ & \\
\hline Upper & $297(85.8)$ & $211(74.8)$ & \\
\hline Diet pattern & & & 0.046 \\
\hline Normal & $299(86.4)$ & $258(91.5)$ & \\
\hline Abnormal & $47(13.6)$ & $24(8.5)$ & \\
\hline Snacks & & & 0.014 \\
\hline No & $50(14.5)$ & $23(8.2)$ & \\
\hline Yes & $296(85.5)$ & $259(91.8)$ & \\
\hline Exercise & & & 0.769 \\
\hline Yes & $327(94.5)$ & $268(95.0)$ & \\
\hline No & $19(5.5)$ & $14(5.0)$ & \\
\hline $\mathrm{TV}$ & & & 0.369 \\
\hline$\geq$ 5hours & $30(8.7)$ & $19(6.7)$ & \\
\hline$\leq$ hhours & $316(91.3)$ & 263(93.3) & \\
\hline
\end{tabular}


There were 346 (55.1\%) males and 282 females (44.9\%). The male students were older than the female students $14.47(1.82)$ vs. 13.93(1.58) years, $p<0.001$. But, the mean BMI, SBP, DBP and FPG were significantly higher in female compared to male students: BMI, 20.39(2.82) kg/m² vs. 19.27(2.14) kg/m²; SBP, 122.61(13.91) $\mathrm{mmHg}$ vs. 114.36(14.82) $\mathrm{mmHg}$; DBP, 75.76(10.96) $\mathrm{mmHg}$ vs. 65.29(9.69) mmHg; FPG, 97.60(10.52) mg/dl vs. 93.40(10.84) mg/ $\mathrm{dl}$, all $\mathrm{P}<0.001$. More females had general obesity, $(13.2 \%$ vs. $2.3 \%$, $\mathrm{p}<0.001)$, were in the low/middle social class $(25.2 \%$ vs. $14.2 \%$, $\mathrm{p}=0.000)$, and consumed more snacks ( $91.8 \%$ vs. $85.5 \%, \mathrm{p}=0.014$ ) than their male counterparts (Table 1). Girls were nine times more likely to develop obesity compared to boys [OR (95\%CI), 8.685(3.872-19.483), $\mathrm{p}<0.001$ ]. Similarly, those in public schools were eight times more likely to develop obesity than those in private schools [OR (95\%CI), 8.149(1.047-63.426, p=0.045). Factors such as social class, intake of snacks, physical inactivity, family size, and family history of obesity and spending long hours with television did not significantly predict general obesity (Table 2).

Table 2: Predictors of general obesity among adolescents.

\begin{tabular}{|c|c|c|c|}
\hline Predictor Variable & Reference Variable & B & 95\%CI \\
\hline Type of school & Private & 8.149 & $1.047-63.426$ \\
\hline Family size & Small & 0.501 & $0.191-1.312$ \\
\hline Social class & Lower/middle & 1.751 & 0.160 \\
\hline Snacks & Takes snacks & $1.757-4.009$ & $0.611-5.053$ \\
\hline Physical inactivity & Yes & 0.752 & $0.203-2.778$ \\
\hline Ownership of handset & Yes & 0.81 & $0.404-1.627$ \\
\hline TV hrs & $\geq 5$ hours & 0.615 & $0.197-1.916$ \\
\hline Family history of obesity & Present & 0.647 & $0.429-1.274$ \\
\hline Sex & Male & 8.685 & $3.872-19.483$ \\
\hline
\end{tabular}

\section{Discussion}

Obesity among children and adolescents is increasing globally. Eight percent of the adolescents in the index study population were obese; $83 \%$ of the obese adolescents were female while the remaining $17 \%$ were male. There were also significant statistical differences in the age, height, BMI, waist circumference, fasting blood glucose, systolic and diastolic blood pressures of the female adolescents compared to their male counterparts. The index study shows that female adolescents were nine times more likely to develop obesity compared to their female counterpart. This finding is in agreement with previous studies on obesity within and outside Africa [16, 20-22]. This can partly be explained by earlier onset of puberty in females compared to the males and the fact that there is usually increased growth velocity in the early phase of puberty in female while growth spurt occurs in the middle and late phases of puberty in male adolescents. Since childhood obesity is a risk factor for adult obesity, women would be expected to be more burdened with the disease than men. Indeed previous report showed that obesity was more prevalent among women [23]. Specifically, it was shown that for a man with obesity, eleven women were more likely to develop the disease [23]. One of the reasons given for more obesity among females is the fact that male adolescents engage in more physical activities and exercise than their female counterpart as documented by Sweeting [24] in a research to unravel gendered dimensions of obesity in childhood and adolescence. These findings suggest that female students should be targeted for obesity prevention before adolescence.

The type of school attended by the secondary school adolescents is another significant predictor of general obesity in the index study, apart from female gender. The index study shows that adolescents in public schools were eight times more likely to develop obesity compared to those in private schools. This is contrary to general opinion and reports from previous studies within and outside developing countries [22]. The possible reason for this unexpected finding is the fact that most private schools in Ekiti State, Nigeria, are schools established out of necessity in response to unstable/ unpredictable academic sessions in public school caused by recurrent industrial actions by union of Teachers. Most of the socalled private schools are attended by children from low/ middle social class. The private school included in the index study is not better than Government public schools in term of available facilities, resource persons and quality of education. There are very few private schools that are truly standard private schools patronized by children from high social class. Further studies will be needed to validate the suspected prevalence of obesity among adolescents attending standard private schools in Ekiti State, Nigeria.

The index study also shows that female students tend to belong to lower/middle socioeconomic class, and consume snacks more than the boys. Even though these factors did not predict obesity, it may contribute to the gender difference in the prevalence of obesity. Previous studies [20-27] have also linked obesity with low socioeconomic class and some of the reasons given include: restricted access to healthy food and health care, negative influence of low socioeconomic status on health-related behaviours like physical activities, dietary behaviours and psychosocial factors like insecurity, stress, isolation and control over life. Demment et al. [28] in a study on the effect of changing income of parents on overweight and obesity among children aged 2 to 15 years demonstrated that 
children who remained low income throughout childhood were more likely to maintain overweight and children who moved into low income during childhood were more likely to be obese.

\section{Conclusion}

Female gender and type of school attended were the predictors of obesity in secondary school adolescents in Ekiti State. Lifestyle changes targeted at female students in public schools may help curb obesity prevalence in the State.

\section{References}

1. Bibiloni MDM, Pons A, Tur JA (2013) Prevalence of overweight and obesity in adolescents: a systematic review. ISRN 2013: 392747.

2. Caballero B (2007) The global epidemic of obesity: An overview. Epidemiol Rev 29: 1-5.

3. De Onis M, Blossner M, Borghi E (2010) Global prevalence and trends of overweight and obesity among preschool children. Am J Clin Nutr 92(5): 1257-1264

4. El-Bayoumy I, Shady I, Lotfy H (2009) Prevalence of obesity among adolescents (10-14years) in Kuwait. Asia Pac J Public Health 21(2): 153159.

5. Freedman DS, Mei Z, Srinivasan SR, Berenson GS, Dietz WH (2007) Cardiovascular risk factors and excess adiposity among overweight children and adolescents: the bogalusa heart study. J Pediatr 150(1): 12-17.

6. Lobstein L, Baur R (2004) Obesity in children and young people: a crisis in public health. Obes Rev 5(Suppl 1): 4-104.

7. Oduwole AA, Ladapo TA, Fajolu IB, Ekure EN, Adeniyi OF (2012) Obesity and elevated blood pressure among adolescents in Lagos, Nigeria: a cross-sectional study. BMC Public Health 12: 616.

8. Dietz WH (1998) Health consequences of obesity in youth: childhood predictors of adult disease. Pediatrics 101 (3 Pt 2): 518-525.

9. Lifshitz F (2008) Obesity in children. J Clin Res Pediatr Endocrinol 1(2): 53-60.

10. Wang Y, Lobstein T (2006) Worldwide trends in childhood overweight and obesity. Int J Pediatr Obes 1(1): 11-25.

11. Senbajo IO, Adejuyigbe EA (2007) Prevalence of overweight and obesity in Nigerian preschool children. Nutr Health 18(4): 391-399.

12. Rooney BL, Mathiason MA, Schauberger CW (2011) Predictors of obesity in childhood, adolescence and adulthood in a birth cohort. Matern Child Health J 15(8): 1166-1175.

13. Lassera AM, Chiolero A, Cachat F, Paccaud F, Bovet P (2007) Overweight in Swiss children and associations with children's and parents characteristics. Obesity (Silver Spring) 15(12): 2912-2919.
14. Padez C, Mourao I, Moreira P, Rosado V (2005) Prevalence and risk factors for overweight and obesity in Portuguese children. Acta Paediatr 94(11): 1550-1557.

15. Ortega FB, Ruiz JR, Sjostrom M (2007) Physical activity, overweight, and central adiposity in Sweden children and adolescents: the European Youth Heart Study. Int J Behav Nutr Phys Act 4: 61.

16. Apfelbacher CJ, Loerbroks A, Cairns J, Behrendt H, Ring J, et al. (2008) Predictors of overweight and obesity in five to seven year-old children in Germany: Results from cross-sectional studies. BMC Public Health 8: 171.

17. Marfell-Jones M (2006) International Standards for Anthropometric Assessment. International Society for the Advancement of Kinanthropometry, Potchefstroom, South Africa.

18. Ogden CL, Kuczmarski RJ, Flegal KM, Mei Z, Guo S, et al. (2002) Centers for Disease Control and Prevention 2000 growth charts for the United States: improvements to the 1977 National Center for Health Statistics version. Pediatrics 109(1): 45-60

19. American Diabetes Association (2005) Diagnosis and classification of diabetes mellitus. Diabetes Care 28 (Suppl 1): S37- S42.

20. Maruf FA, Aronu U, Chukwuegbu K, Aronu AE (2013) Influence of gender on prevalence of overweight and obesity in Nigerian school children and adolescents. Tanzan J Health Res 15(4): 247-251.

21. Mustapha RA, Sanusi RA (2013) Overweight and obesity among inschool adolescentsin Ondo State, Southwest Nigeria. Afr J Biomed. Res 16: 205-210.

22. Fruhstorfer BH, Mousolis C, Uthman OA, Robertson W (2016) Socioeconomic status and overweight or obesity among school-aged children in sub-Saharan Africa- a systematic review. Clni Obes 6(1): 19-32.

23. Raimi TH, Odunsan O, Fasanmade OA (2015) High prevalence of central obesity in rural South-western Nigerian: need for targeted prevention. J Diabetes Endocrinol 6: 12-18.

24. Sweeting HN (2008) Gendered dimensions of obesity in childhood and adolescence. Nutr J 7: 1 .

25. Moore CJ, Cunningham SA (2012) Social position, psychological stress, and obesity: a systematic review. J Acad Nutr Diet 112(4): 518-526.

26. Kim TJ, Vondem Knesebeck O (2018) Income and obesity: what is the direction of the relationship? A systematic review and meta-analysis. BMJ Open 8(1): e019862.

27. Gonzalez-Casanova I, Sarmiento OL, Pratt M, Gazmararian JA, Martorell R, et al. (2014) Individual, family, and community predictors of overweight and obesity among Colombian children and adolescents. Prev Chronic Dis 11: e134.

28. Demment MM, Haas JD, Olson CM (2014) Changes in family income status and the development of overweight and obesity from 2 to 15 years: a longitudinal study. BMC Public Health 14: 417.
Creative Commons Attribution 4.0 International License

For possible submissions Click Here

\section{Submit Article}

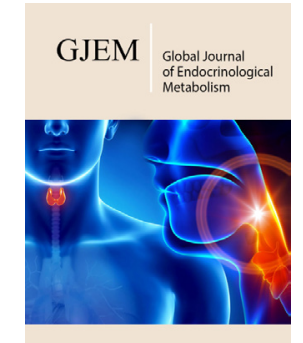

Global Journal of Endocrinological Metabolism

\section{Benefits of Publishing with us}

- High-level peer review and editorial services

- Freely accessible online immediately upon publication

- Authors retain the copyright to their work

- Licensing it under a Creative Commons license

- Visibility through different online platforms 